\title{
Research on Risk Management of Wise Medical Project under the PPP Mode
}

\author{
Qian Wang ${ }^{1, a}$, Xiaoyu Wang ${ }^{2, b^{*}}$ and Li Hou ${ }^{3, c}$ \\ 1, 2, 3 Department of Information Technology and Business Management \\ aawangqian@neusoft.edu.cn, ’wangxiaoyu@neusoft.edu.cn, chouli@neusoft.edu.cn \\ ${ }^{*}$ The Corresponding author
}

Keywords: PPP mode; Project risk evaluation; AHP

\begin{abstract}
In this paper, based on the wise medical project under the PPP model, constructs the risk index system after the risk identification, and uses the AHP to evaluate the project risks, constructs the judgement matrix, determines weights and sort.
\end{abstract}

\section{Overview}

As the country's first demonstration city of smart city, Dalian strengthens the wisdom medical construction to a high strategic level. With modern information technology and communication technology, wise medical maximizes the sharing of medical and health information, through the deep integration of technology and application. Because of the large investment, long construction period and complex technology, the wise medical project maybe meet more unforeseen situation, increases the variety of risk factors. In the traditional mode, the results of the government's construction are not satisfactory. It must adopt a new model to realize sustained development. The new mode is that constructing public information service platform based on PPP model, operating platform by the enterprise, providing data services to the government[1][2].

\section{PPP Mode}

Compared with foreign mature PPP model research, the research is still at the primary stage in China. With the continuous development of social economy in China, the PPP model is being widely used. The PPP project has its advantages, but it does not mean that there is no risk. Due to the PPP projects involve large amount of funds, have various stakeholders and the construction period is long, etc., they are also facing great risk, in fact [3][4].

\section{Application of AHP in Risk Evaluation}

Risk Identification. According to the wise medical projects have the characteristics of hardware and software integration, this project uses WBS to identify risk, identifies the risks list that may have an impact on the project, and indentifies their influence rules.

Risk Evaluation Index System. In this paper, the analytic hierarchy process (AHP) is used to quantify the probability and impact of project risk. According to the risk identification, this paper establishes the evaluation index system [5], as shown in Fig. 1. 


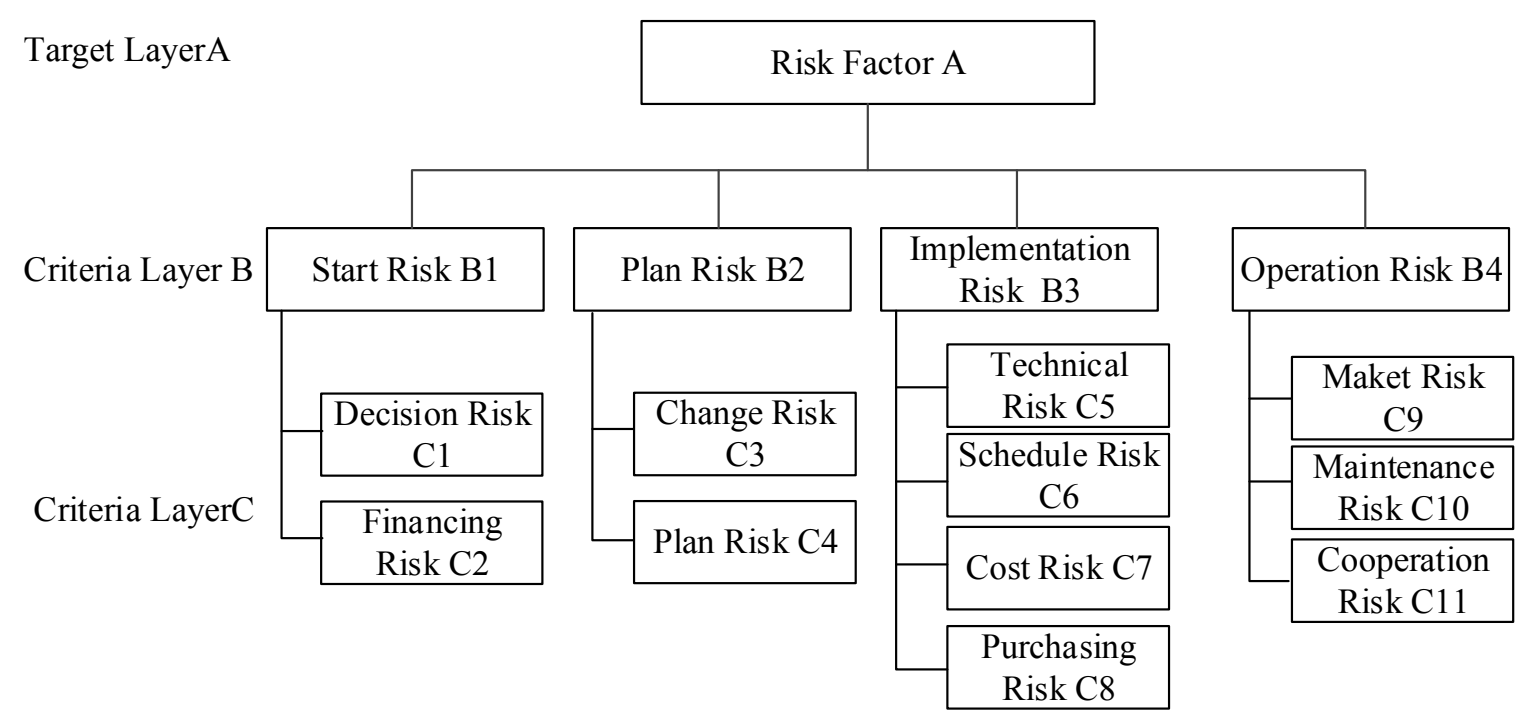

Figure 1. Finite the evaluation index system

Risk Evaluation Model. Based on the establishment of hierarchical structure, this paper constructs comparison judgment matrix. This paper compares according to the risk impact and occurrence probability of the layer B. The scale of importance is $1 \sim 9$ scale, as shown in Table 1 .Then this paper compares according to the criterion layer $\mathrm{C}$, as shown in Table 2-Table 5.

Table 1 Matrix A

\begin{tabular}{|c|c|c|c|c|}
\hline $\mathrm{A}$ & $\mathrm{B}_{1}$ & $\mathrm{~B}_{2}$ & $\mathrm{~B}_{3}$ & $\mathrm{~B}_{4}$ \\
\hline $\mathrm{B}_{1}$ & 1 & 3 & $1 / 3$ & 3 \\
\hline $\mathrm{B}_{2}$ & $1 / 3$ & 1 & $1 / 5$ & 1 \\
\hline $\mathrm{B}_{3}$ & 3 & 5 & 1 & 5 \\
\hline $\mathrm{B}_{4}$ & $1 / 3$ & 1 & $1 / 5$ & 1 \\
\hline
\end{tabular}

Table 2 Matrix B1

\begin{tabular}{|c|c|c|}
\hline $\mathrm{B}_{1}$ & $\mathrm{C}_{1}$ & $\mathrm{C}_{2}$ \\
\hline $\mathrm{C}_{1}$ & 1 & $1 / 3$ \\
\hline $\mathrm{C}_{2}$ & 3 & 1 \\
\hline
\end{tabular}

Table 4 Matrix B3

\begin{tabular}{|c|c|c|c|c|}
\hline $\mathrm{B}_{3}$ & $\mathrm{C}_{5}$ & $\mathrm{C}_{6}$ & $\mathrm{C}_{7}$ & $\mathrm{C}_{8}$ \\
\hline $\mathrm{C}_{5}$ & 1 & 3 & 3 & 5 \\
\hline $\mathrm{C}_{6}$ & $1 / 3$ & 1 & 1 & 3 \\
\hline $\mathrm{C}_{7}$ & $1 / 3$ & 1 & 1 & 3 \\
\hline $\mathrm{C}_{8}$ & $1 / 5$ & $1 / 3$ & $1 / 3$ & 1 \\
\hline
\end{tabular}

Table 3 Matrix B2

\begin{tabular}{|c|c|c|}
\hline B2 & C3 & C4 \\
\hline C3 & 1 & 1 \\
\hline C4 & 1 & 1 \\
\hline
\end{tabular}

Table 5 Matrix B4

\begin{tabular}{|c|c|c|c|}
\hline $\mathrm{B}_{4}$ & $\mathrm{C}_{9}$ & $\mathrm{C}_{10}$ & $\mathrm{C}_{11}$ \\
\hline $\mathrm{C}_{9}$ & 1 & 1 & 1 \\
\hline $\mathrm{C}_{10}$ & 1 & 1 & 1 \\
\hline $\mathrm{C}_{11}$ & 1 & 1 & 1 \\
\hline
\end{tabular}

Single Level Sorting and Consistency Check. To a certain level, all the elements of this layer should be discharged. This problem can be summed up as the problem of computing the eigenvalues and eigenvectors of judgement matrix, the formula as follows:

$$
A W=\lambda W
$$




$$
\lambda_{\max }=\sum_{i=1}^{n} \frac{(\mathrm{AW})_{i}}{n W_{i}}
$$

Among them, $\mathrm{W}$ is the eigenvector corresponding to the judgment matrix $\mathrm{A}, \lambda_{\max }$ is the largest eigenvalue of $\mathrm{A}$. The problem is transformed into solving $\lambda_{\max }$ and $\mathrm{W}$, that is the relative weight.

In this paper, the relative weight of each element of judgment matrix is calculated by using the addition method. According to Table 1- Table 4, this paper repeats step (a) to step (e), calculates the maximum eigenvalues of each matrix:

(a)the judgment matrix is normalized by column: $\mathrm{b}_{\mathrm{ij}}=\mathrm{a}_{\mathrm{ij}} / \Sigma \mathrm{a}_{\mathrm{ij}}$

(b)sum by row: $\mathrm{c}_{\mathrm{i}}=\sum \mathrm{b}_{\mathrm{ij}}(\mathrm{i}=1,2,3 \ldots \mathrm{n})$

(c)normalize $\mathrm{C}_{\mathrm{i}}$, get eigenvector: $\mathrm{W}=\left(\mathrm{w}_{1}, \mathrm{w}_{2}, \ldots, \mathrm{w}_{\mathrm{n}}\right) \mathrm{T}, \mathrm{w}_{\mathrm{i}}=\mathrm{c}_{\mathrm{i}} / \Sigma \mathrm{c}_{\mathrm{i}}$;

(d)according to Eq. 1, calculate characteristic root $\lambda$;

(e)according to Eq. 2 , calculate the maximum eigenvalue $\lambda_{\max }$;

Because the judgment matrix is the comparison between the elements with each other, and there is no fixed reference, so it is possible to make a judgment against common sense, that is not consistent. Such as $\mathrm{A}>\mathrm{B}, \mathrm{B}>\mathrm{C}$, and $\mathrm{C}>\mathrm{A}$. The more the order of the judgment matrix, the more serious the inconsistency will be[6][7][8]. The formula for calculating the consistency indicator is as follows:

$$
C I=\frac{\lambda_{\max }-n}{n-1}
$$

In Eq. 3, $\lambda \max$ is the largest eigenvalue of the judgement matrix, $\mathrm{n}$ is the order of the judgement matrix.

Comparing between $\mathrm{CI}$ and the mean random consistency index RI, we can check whether the judgment matrix has satisfactory consistency, the formula is as follow:

$$
C R=\frac{C I}{R I}
$$

When $\mathrm{CR}<0.1$, it is considered that the judgment matrix has satisfactory consistency; otherwise, CI need to be readjusted until $\mathrm{CR}<0.1$.

Total Order Sorting. It can calculate the importance of each factor to the overall index ,after obtaining the relative importance of each level element.

As shown in Fig. 1, layer $B$ has $m$ elements: $B_{1}, B_{2}, \ldots, B_{m}$, their importance to the total value: $\mathrm{W}_{1}, \mathrm{~W}_{2}, \ldots, \mathrm{W}_{\mathrm{m}}$, layer $\mathrm{C}$ has $\mathrm{n}$ elements: $\mathrm{C}_{1}, \mathrm{C}_{2}, \ldots, \mathrm{C}_{\mathrm{n}}$. The importance of factor $\mathrm{C}_{\mathrm{i}}$ to $\mathrm{B}_{\mathrm{j}}$ is $\mathrm{V}_{\mathrm{ij}}$, then, the importance of factor $\mathrm{C}_{\mathrm{i}}$ is:

$$
W_{i}=\Sigma_{j} W_{j} V_{i j}
$$

The total sort table can be obtained by calculation, see Table 6 .

As shown in Table 6, the greatest impact on project implementation is the technical risk $\mathrm{C} 5$. The basic technology chain of the wise medical is still not perfect, it still lags behind the developed countries, especially in the side of the information technology independent intellectual property rights[9][10]. This is consistent with the development of current domestic wise medical project. 
Table 6 The total sort table

\begin{tabular}{|c|c|c|c|c|c|}
\hline \multirow{2}{*}{ hierarchy } & $\mathbf{B 1}$ & $\mathbf{B 2}$ & $\mathbf{B 3}$ & $\mathbf{B} 4$ & \multirow{2}{*}{ total sort } \\
\cline { 2 - 5 } & 0.1747 & 0.0962 & 0.2091 & 0.1435 & \\
\hline $\mathrm{C}_{1}$ & 0.547 & 0.1222 & 0.5454 & 0.6544 & 0.0428 \\
\hline $\mathrm{C}_{2}$ & 0.1546 & 0.6451 & 0.2121 & 0.3845 & 0.0904 \\
\hline $\mathrm{C}_{3}$ & 0.6248 & 0.0235 & 0.6544 & 0.5213 & 0.0842 \\
\hline $\mathrm{C}_{4}$ & 0.2546 & 0.2654 & 0.3665 & 0.5416 & 0.0513 \\
\hline $\mathrm{C}_{5}$ & 0.054 & 0.9412 & 0.1546 & 0.5216 & 0.0927 \\
\hline $\mathrm{C}_{6}$ & 0.0468 & 0.2468 & 0.244 & 0.5416 & 0.0515 \\
\hline $\mathrm{C}_{7}$ & 0.2495 & 0.1432 & 0.11323 & 0.132 & 0.0449 \\
\hline $\mathrm{C}_{8}$ & 0.6872 & 0.5421 & 0.2854 & 0.516 & 0.0363 \\
\hline $\mathrm{C}_{9}$ & 0.0468 & 0.2468 & 0.244 & 0.5416 & 0.0415 \\
\hline $\mathrm{C}_{10}$ & 0.2495 & 0.1432 & 0.11323 & 0.132 & 0.0409 \\
\hline $\mathrm{C}_{11}$ & 0.6872 & 0.5421 & 0.2854 & 0.516 & 0.0335 \\
\hline
\end{tabular}

The second degree of influence is the project financing risk C2. PPP project involves a large number of financing loans, even includes foreign institutions sometimes, so the project financing has great impact on the project.

The low-ranking risk factors are purchasing risk and operation risks and so on. This shows that compared to other risk factors, the project is less affected by the operational level and market factors.

\section{Summary}

In the early planning stage of the project, it is necessary to identify the risks that may be faced in the process of project implementation, evaluate the impact of these risk factors. For the new project that its reference is less, AHP method can be used for risk evaluate, to provide the relevant decision-making and planning for project decision makers.

\section{References}

[1] X.C. Zheng, Y. Sun and G.J. Yu: Journal of Medical Informatics, Vol. 34 (2013) No.1, p.10.

[2] J.G. Li, X.Y. Tang: Journal of Medical Informatics, Vol. 18 (2013) No.6, p.1.

[3] X. Deng: International Finance, Vol. 10 (2015) No.10, p.75.

[4] L. Zhang: Research on Risk Analysis of PPP Model (Institute of Fiscal Science Ministry of Finance, Master, China 2015), p.28.

[5] P.D. Sang, W. Zhang: Project Management Technology, Vol. 14 (2016) No.12, p.116.

[6] J. Dong: Technology Information, Vol. 29 (2015) No.29, p.218.

[7] H.D. Zhang, C.M. Shuai and Q. Guo: Journal of Safety Science and Technology, Vol. 10 (2014) No.4, p.152.

[8] C.M. Wan, L. Lin: Modern Commerce Industry, Vol. 36 (2015) No.1, p.94.

[9] S.S. Wang, B. Wu: China Science and Technology Rewiew, Vol. 44 (2015) No.44, p.178.

[10]B.J. Zhang: AHP and Application Case (Electronic Industry Press, China 2014). 